Original article

\title{
Existing practices of intravenous (IV) medication management and barriers for safe practices among healthcare professionals in a selected hospital of Udupi district, Karnataka
}

\author{
Madhurikranta Mukherjee $^{\mathrm{a}}$, Sushmitha R. Karkada ${ }^{\mathrm{a}}$, Shobha ${ }^{\mathrm{a}, *}$, K.E. Vandana ${ }^{\mathrm{b}}$ \\ ${ }^{a}$ Department of Obstetrics \& Gynecological Nursing, Manipal College of Nursing MAHE Manipal, Karnataka, India \\ ${ }^{\mathrm{b}}$ Microbiology Kasturba Medical College, MAHE Manipal, Karnataka, India
}

\section{Introduction}

Safety is a concept followed worldwide that holds within capability, the reactivity of caregivers, security of care and satisfaction of patients and family members. One of the main aims of health care betterment is patient safety. Drug errors are repeated mistakes and can create various adverse effects.

Depending on the statistics surveyed, the annual death rate due to medication error is 44000-40, 00,000. According to the United States Food and Drug administration report (2009), minimum one death happens each day and 1.3 million people get injured, due to drug errors. $^{2}$

The National Coordinating Council for Medication Error Reporting and Prevention (NCC MERP) defines a "medication error" as "any preventable event that may cause or lead to inappropriate medication use or patient harm while the medication is in the control of the health care professionals, patient or consumers". ${ }^{3}$

An article published in "The Times of India" on 21st September, 2013 reported that India has a massive, 5.2 million injuries each year because of medical errors and its adverse effects. Among these, the major causes are medications errors and hospital-acquired infections. Likewise, about 3 million individuals' years of healthy life are lost every year in India because of these injuries. ${ }^{4}$

Assessing the existing safe IV medication practices periodically and exploring the reasons behind medication errors is important to find out the gaps in order to reduce healthcare associated medication errors and infection rate. And it is vital to identify factors for safe IV medication practices.

The objectives of the study were to assess the existing practices among healthcare professionals regarding IV medication management and to identify the barriers for safe IV medication management among healthcare professionals.

\section{Materials and methods}

This study was conducted in selected wards of a tertiary referral hospital of Southern India among healthcare professionals. The data was collected from 2nd January 2017 to 4th February 2017. After obtaining administrative permission and Institutional Ethics Committee (770/2016) approval, concealed observation of events such as assessing safe IV medication management practice was observed. After that, the healthcare professionals in the units were explained about the concealed observation and informed consent was sort. Healthcare professionals willing to participate were explained about the study and the participant information sheet was given to them. They were asked to complete the 5-point Likert Scale which was aimed to identify the barriers of safe IV medication management practices.

The researcher developed observation checklist based on Center for Disease Control (CDC), ${ }^{5}$ Institute for Safe Medication Practices guidelines (ISMP) ${ }^{6}$ and World Health Organization. ${ }^{7}$ A total of 90 events of IV medication management were observed by using an observational checklist. The tool consisted of 33 items with 16 critical steps, under three categories namely preparation of patient, preparation of medicine from vial and ampoule, and administration of medication. Each item had one correct response. Concealed observation of event was done when a medication was prepared either from the vial or ampoule.

A 5-point Likert scale was developed which consisted of 11 items and had five responses namely 'strongly disagree', 'disagree', 'uncertain', 'agree' and 'strongly agree'.

The data were analyzed using descriptive statistics by using SPSS (statistical package of social science) version 16 software.

\section{Results}

The study results show that, among 30 participants majority 21 (70\%) of the healthcare professionals belonged to the age group of $22-25$ years, $22(73.3 \%)$ of them were GNM qualified, $16(53.3 \%)$ of them had one to two years of work experience, and most 28 (93.3\%) of

\footnotetext{
* Corresponding author.

E-mail address: kamathnvr@gmail.com (Shobha).
} 
Table 1

Socio demographic characteristics.

\begin{tabular}{|c|c|c|c|}
\hline \multicolumn{4}{|l|}{$\mathrm{N}=30$} \\
\hline Sample characteristics & Frequency(f) & \multicolumn{2}{|c|}{ Percentage (\%) } \\
\hline \multicolumn{4}{|l|}{ Age (in years) } \\
\hline $22-25$ & 21 & & 70 \\
\hline $26-29$ & 7 & & 23.3 \\
\hline$>30$ & 2 & & 6.7 \\
\hline \multicolumn{4}{|c|}{ Professional qualification } \\
\hline GNM & 22 & & 73.3 \\
\hline Post Basic & 2 & & 6.7 \\
\hline BSc Nursing & 6 & & 20 \\
\hline MSc Nursing & 0 & & 0 \\
\hline \multicolumn{4}{|c|}{ Total years of experience } \\
\hline$<1$ & 3 & & 10 \\
\hline $1-2$ & 16 & & 53.3 \\
\hline $3-4$ & 2 & & 6.7 \\
\hline$>4$ & 9 & & 30 \\
\hline \multicolumn{4}{|c|}{ CNE sessions attended on IV medication management } \\
\hline Yes & 28 & & 93.3 \\
\hline No & 2 & 6. & \\
\hline \multicolumn{4}{|l|}{ Previous area of work } \\
\hline OBG Ward & 24 & 80 & \\
\hline Others & 6 & 20 & \\
\hline
\end{tabular}

the healthcare professionals had attended continuing Nursing Education (CNE) sessions on IV medication management. Majority 24 $(80 \%)$ of the healthcare professionals were working in Obstetrics and Gynecological (OBG) wards (see Table 1).

The data presented in Table 2 showed that in the preparation phase among 90 events observed all healthcare professionals had reviewed patient profile and in 86 (95.6\%) of the events appropriate sized syringe was selected for preparation of IV medication. Whereas none of the healthcare professionals checked the expiry date of medication and did not perform double checking of medication. Majority 87 (96.7\%) of the events, aseptic techniques were not followed during the preparation of IV medication, $81(90 \%)$ of the events proper hand hygiene prior to preparation and $78(86.7 \%)$ events after preparation of IV medication was not performed.

In the administration phase, among 90 events observed, all healthcare professionals identified the patient properly, administered medication and disposed of the syringe, needle and cotton swab as per the Biomedical Waste Management policy. Majority 89 (98.9\%) of the events, healthcare professionals had secured the saline lock clamp and $74(82.2 \%)$ events documentation was done immediately after administration of medication. Whereas none of the healthcare professionals used any personal protective equipment (PPE) while administering IV medication, 84 (93.3\%) injection port was not cleaned with spirit swab, and in $78(86.7 \%)$ events proper hand hygiene after administration of

Table 2

Frequency (f) \& Percentage (\%) of existing IV medication management practices.

After the sample size calculation, it was decided to observe 30 healthcare professionals 3 times each, so a total of 90 events on IV medication management practices were observed. Items on IV medication management practices were categorized under the following headings as preparation (from ampule and vial) and administration.

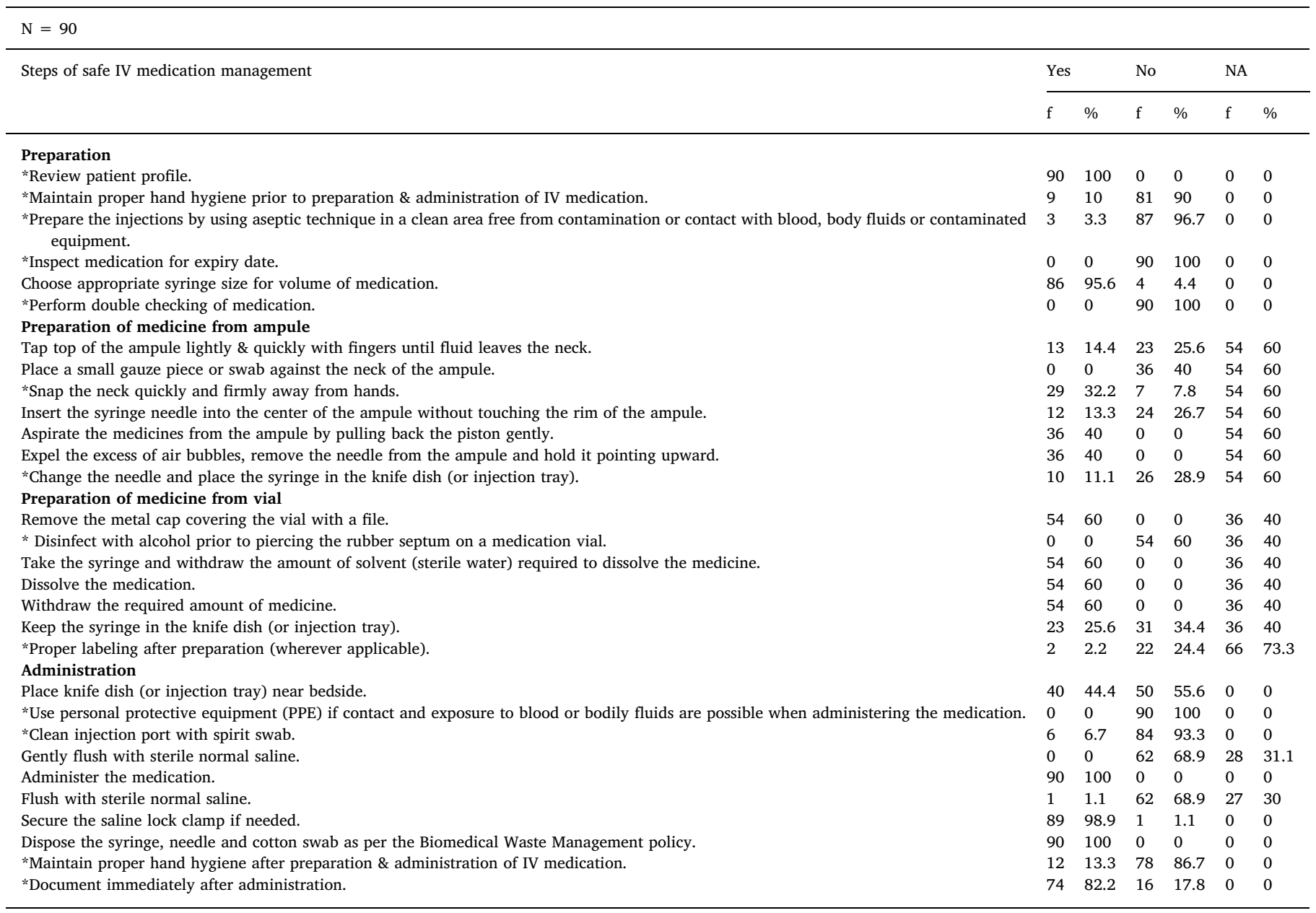

Note:*Critical points, NA means not applicable, observation was done either from ampule or vial at a time. 
Table 3

Frequency \& Percentage Distribution of barriers for the safe IV medication management practices among healthcare professionals.

The tool consisted of 11 items which had five responses namely 'strongly disagree', 'disagree', 'uncertain', 'agree' and 'strongly agree'. Table 3 represented the frequency and percentage distribution of barriers for safe IV medication management practices.

\begin{tabular}{|c|c|c|c|c|c|c|c|c|c|c|}
\hline \multirow[t]{2}{*}{ Barriers for safe IV medication management practice } & \multicolumn{2}{|c|}{ Strongly Disagree } & \multicolumn{2}{|c|}{ Disagree } & \multicolumn{2}{|c|}{ Uncertain } & \multicolumn{2}{|c|}{ Agree } & \multicolumn{2}{|c|}{ Strongly Agree } \\
\hline & $\mathrm{f}$ & $\%$ & $\mathrm{f}$ & $\%$ & f & $\%$ & $\mathrm{f}$ & $\%$ & f & $\%$ \\
\hline Excessive work load & 0 & 0 & 3 & 10 & 0 & 0 & 23 & 76.7 & 4 & 13.3 \\
\hline Inadequate nurse patient ratio & 0 & 0 & 4 & 13.3 & 1 & 3.3 & 22 & 73.3 & 3 & 10 \\
\hline Unavailability of resources & 0 & 0 & 26 & 86.7 & 2 & 6.7 & 2 & 6.7 & 0 & 0 \\
\hline Unavailability of fellow nurses for cross checking of medication & 2 & 6.7 & 24 & 80 & 2 & 6.7 & 1 & 3.3 & 1 & 3.3 \\
\hline Lack of supervision while preparation \& administration of medication & 3 & 10 & 25 & 83.3 & 1 & 3.3 & 1 & 3.3 & 0 & 0 \\
\hline Lack of time & 0 & 0 & 4 & 13.3 & 4 & 13.3 & 20 & 66.7 & 2 & 6.7 \\
\hline Lack of knowledge of practice regarding safe IV medication management. & 4 & 13.3 & 23 & 76.7 & 1 & 3.3 & 2 & 6.7 & 0 & 0 \\
\hline Causing minimum chance of infection. & 0 & 0 & 14 & 46.7 & 5 & 16.7 & 9 & 30.3 & 2 & 6.7 \\
\hline Non-touch technique is not needed. & 7 & 23.3 & 18 & 60 & 0 & 0 & 5 & 16.7 & 0 & 0 \\
\hline Maintaining hand hygiene, which is time- consuming & 4 & 13.3 & 11 & 36.7 & 0 & 0 & 15 & 50 & 0 & 0 \\
\hline Lack of positive reinforcement & 2 & 6.7 & 18 & 60 & 2 & 6.7 & 8 & 26.7 & 0 & 0 \\
\hline
\end{tabular}

IV medication was not followed. In 27 (30\%) events, flushing IV cannula was not performed, as the patients were already on continuous IV fluids.

The data presented in Table 3 shows that majority $23(76.7 \%)$ of the health care professionals expressed excessive workload as a barrier for safe IV medication management practices, whereas the least, 1 (3.3\%) reported unavailability of fellow nurses for cross checking of medication \& lack of supervision was a barrier.

\section{Discussion}

The present study was supported by a prospective study conducted to identify the incidence, types and factors related to parenteral medication preparation or administration errors done by the staff nurses in a General Intensive Care Unit (GICU) in Malaysia which revealed that out of 122 parenteral doses observed, none of them performed double checking of medication $122(100 \%)$. In $15(12 \%)$ doses, syringes were not properly labeled, $14(11 \%)$ doses aseptic techniques were not followed and $9(7 \%)$ doses prescription, patient identification data and allergy status was not reviewed by the staff nurses before administration of the medication. ${ }^{8}$

The present study findings were contradicted with a prospective observational study done to assess the frequency, type and severity of IV medication errors and its association with errors, procedural failure in two well-known University Hospitals in Sydney, Australia. The study result showed that out of 568 IV medication administration observed, majority $552(97.2 \%)$ of the events, nurses checked the medication label before administration, 544 (95.8\%) cross-checked the medication with other fellow nurses before administration and 511 (90.0\%) maintained aseptic techniques. ${ }^{9}$

The present study was supported by a survey done to identify the causes of medication errors by staff nurses, a 5 point Likert scale was given to 119 staff nurses. The study results revealed that majority of them 59 (49.6\%) agreed with excessive work pressure, 51 (42.9\%) tiredness resulting from overworking, lack of time 49 (41.2\%) and insufficient nurse patient ratio causes medication errors. ${ }^{10}$

Also the present study was supported by a prospective, observational study conducted in General Medicine and Pediatric ward of Civil Hospital, Ahmedabad during October 2012 to January 2014 to determine the nature and types of medication errors (MEs), to evaluate occurrence of drug-drug interactions (DDIs), and assess rationality of prescription orders. A total of 1109 patients (511 in Medicine and 598 in Pediatric ward) were included during the study period. Total number of Medication Errors (ME) was 403 (36\%) of which, 195 (38\%) were in Medicine and 208 (35\%) were in Pediatric wards. The most common ME was Prescription Errors (PE) 262 (65\%) and Administration Errors was $126(31 \%)$. A potential significant Drug to Drug Interaction (DDI) were observed in $191(17 \%)$ and serious DDIs in $48(4 \%)$ prescriptions. Majority of prescriptions were semirational 555 (53\%) followed by irrational $317(30 \%)$, while $170(17 \%)$ prescriptions were rational. ${ }^{11}$

\section{Conclusion}

Assessing IV medication management practices is a crucial task to reduce the medication error rates as well as infection rates. Health care professionals play a vital role in IV medication management practices, so they should be aware of their existing practices. The similar study can be replicated on a larger sample taken from different wards, and also the study can be done in two parts i.e. administrative level and health care professional's level for improvement of the existing IV medication management practices. A qualitative study can also be conducted among staff nurses to find out the barriers of safe IV medication management practices.

\section{Declaration of competing interest}

All authors report no conflict of interest relevant to this article.

\section{Acknowledgement}

This study was partly supported by Dr. T.M.A Pai Endowment Chair on Antimicrobial Stewardship by Manipal University, Manipal.

Also the authors would like to sincerely thank all the participants for their wholehearted cooperation and timely help throughout the study.

\section{References}

1. Orgeas MG, Phillippart F, Bruel C, Max A, Lau N, Misset B. Overview of medical errors and adverse effects. Spin. 2012;2.

2. Rosiek A, Leksowski K. Medication errors: the role of societal attributes. Organizational Culture. 2016:01-19.

3. Rehan HS, Bhargava S. Medication errors are preventable. Pharmacovigilance: an open acess journal. 2015:1-3.

4. Sinhal K. India Records 5.2 Million Medical Injuries a Year. The Times of India; 2013 Available from: http://timesofindia.indiatimes.com/india/india-records-5-2-millionmedical-injuries-a-year/articleshow/22832260.cms.

5. Siegel JD, Rhinehart E, Jackson M, Chiarello L. Guideline for isolation precautions:preventing transmission of infectious agents in healthcare settings. . Available from: https://www.cdc.gov/infectioncontrol/guidelines/isolation/; 2017.

6. Institute for safe medication practices. . Available from: http://www.ismp.org/Tools/ guidelines/IVSummitPush/IVPushMedGuidelines.pdf; 2015.

7. Organization WH, ed. WHO Best Practices for Injections and Related Procedures Toolkit. Geneva, Switzerland: WHO Document Production Services; 2010.

8. Yin TS, Said MM, Rahaman RA, Taha NA. An investigation of errors:the preparation and administration of parenteral medications in an intensive care unit of a tertiary 
teaching hospital in malayasia. Int J Pharm Pharm Sci. 2016;8(3):325-329.

9. Westbrook JI, Rob MI, Woods A, Parry D. Errors in the administration of intravenous medications in hospital and the role of correct procedures and nurse experience. $\mathrm{Br}$ Med J. 2011:1027-1034. https://doi.org/10.1136/bmjqs-2011-000089.

10. Pournamdar Z, Zare S. Survey of medication error factors from nurses' perspective.
Biology and Medicine(Aligarh):an open acess journal. 2016;8(5):1-4. https://doi.org/ 10.4172/0974 8369.1000310.

11. Patel N, Desai M, Shah S, Patel P, Gandhi A. A study of medication errors in a tertiary care hospital. Prospectives in Clinical Research. 2016;7(4):168-173. 